\title{
GO supported Schiff base/palladium complex: a superior catalyst for the hydrogenation of nitroarenes
}

\author{
A. M. Tolba ${ }^{a}$, E. A. El-Sharkawy ${ }^{b^{*}}$, Hassan M. A. Hassan ${ }^{b, c^{*}}$, Reda F. M. Elshaarawy ${ }^{b}$, N. B. El- \\ Assy $^{\mathrm{a}}$ \\ ${ }^{a}$ Department of Chemistry, Faculty of Science, Arish University, Arish, Egypt \\ ${ }^{b}$ Department of Chemistry, Faculty of Science, Suez University, Suez, Egypt \\ ${ }^{\mathrm{C}}$ Department of Chemistry, College of Science, Jouf University, PO Box 2014, Sakaka, Saudi Arabia
}

\section{ARTICLE INFO}

Article history:

Received 1 June 2020

Received in revised form 7 June 2020

Accepted 8 June 2020

Available online 9 June 2020

\section{Keywords}

Graphene oxide,

Reduction of nitrobenzene,

Schiff base,

Heterogeneous catalyst.

\begin{abstract}
Reducing nitroarenes to the appropriate amines is a major chemical reaction in all industrial and environmental perspectives. In this work, a novel palladium (II) Schiff/base complex supported on graphene oxide (GO) was synthesized via a coordination interaction as an efficient heterogeneous catalyst. GO was functionalized with 3-aminopropyltriethoxysilane (3-APTES) by the condensation reaction, and then the imidazolium Schiff base ligand was fabricated from the reaction of 5-(1methylimidazolium)-vanillyl chloride. The synthesized materials were characterized by various techniques including Raman spectroscopy, FTIR, XRD, elementary analysis, TGA, SEM, and TEM. The as-prepared heterogeneous catalyst was applied in the catalytic reduction of nitrobenzene using $\mathrm{NaBH}_{4}$ in aqueous media. The results exhibited excellent catalytic performance and the reaction kinetics followed a pseudofirst-order with rate constant equals to $0.321 \mathrm{~min}^{-1}$. The catalyst was recovered and recycled with high durability even for four catalytic cycles. GO-supported Pd(II) Schiff / base complex is potentially appealing to heterogeneous catalysts for the hydrogenation process.
\end{abstract}

\section{Introduction}

Reducing nitroarenes to the appropriate amines is a major chemical reaction in all industrial and environmental perspectives [1]. Aniline and its derivatives are significant key precursors in various chemical industries such as synthesis of pharmaceuticals, fine chemicals, agrochemicals, pigments, polymers, dyes, and biologically active compounds [2-5]. Moreover, nitro compounds; especially 2-nitrophenol (2-NP) and 4-nitrophenol (4-NP), are classified as hazardous environmental contaminants owing to their strongly stability and solubility and in water and difficult biodegradation [6]. The traditional route for the reduction of nitroarenes by iron or zinc under acidic conditions produces a huge amount of waste [7]. Thus, the development of selective and efficient catalytic systems, based on transition metals, for the transformation of nitro compounds into anilines has attracted a progressive interest.

\footnotetext{
* Corresponding authors:

E-mail addresses: president@suezuniv.edu.eg (E. A. El-Sharkawy)
} h.hassan@suezuniv.edu.eg (Hassan M. A. Hassan)
Recently, metal nanoparticles play a significant role in nanocatalysis field because of the enhancement in the physical and chemical properties upon transition from bulk to nanomaterials improving the catalytic performance [8]. Therefore, the reduction of nitro compounds is usually carried out using various catalytic systems based on transition metals, for instance $\mathrm{Ni}$ [9], Fe [10], Pt [11], Ru [12], $\mathrm{Au}$ [13], and $\mathrm{Ag}$ [14] with diversities of hydrogen sources. Among these metals, Pd nanoparticles have been widely studied as catalysts for synthesize of anilines due to its high surface-to-volume ratio and unique properties such as high selectivity, recyclability and strong interactions with hydrogen $[15,16]$. In addition, hydrogen, sodium borohydride, hydrazine hydrate, ammonia borane, and formic acid are commonly utilized as reductant for nitro-containing compounds [17-21].

In recent years, several homogeneous catalytic systems have been reported for synthesize of amines by the reduction of nitro groups [22-24]. Nevertheless, these homogeneous catalysts have represented a challenge to industrial and pharmaceutical applications due to high cost of preparation, product contamination, and difficult catalyst separation from the reaction media for recycling [25]. Furthermore, the aggregation of nanoparticles with high surface area decreases the catalytic activity of homogeneous systems [26]. Contrariwise, anchorage of metals onto a solid support, to design heterogeneous catalysts, is leading to efficient recovery, and improving 
stability and selectivity of the catalyst [27]. For extremely effective heterogeneous catalysts, indeed, the metal should be extremely active and firmly attached to the support to reduce metal detach and optimize reusability [28]. For these reasons, many researches have been devoted to successfully immobilize transition metals on different solid supports such as mesoporous silica [29], zeolites [30], clays [31], collagen fibers [32], boehmite [33], Metal organic frameworks (MOFs) [21], and carbon nanomaterials [34, 35].

Among different carbon nanomaterials, graphene oxide (GO) has revealed a great interest as an excellent support for the development of a diversity of metallic nanocatalysts, due to its unique electronic properties, chemical and thermal stability, intrinsic porosity, large surface area and high dispersibility in water and other organic solvents [36-40]. GO is a unique two-dimensional $\mathrm{sp}^{2}$ hybrid carbon-based material with a hexagonal network with plenty of chemically reactive functional groups on the basal planes as well as edges i.e. $-\mathrm{COOH}$, epoxy and $-\mathrm{OH}$ groups [41]. Hence, various GO derivatives have been formed through the covalent linkage of organic molecules on GO surface and the silylation adjustment on GO surface is a good example for the preparation of graphene nanocomposites [42]. This silylation process is easily occurred by the reaction of various silane-containing reagents with the active hydroxyl groups on GO. Few investigations have been reported on the synthesis of transition metal complexes to catalyze the reduction of nitro compounds. Schiff bases are versatile organic ligands in coordination chemistry and have been extensively used to synthesize stable metal complexes to catalyze various organic reactions due to their interesting properties such as ease of synthesis and electronic structures [33, 43].

In the present work, we successfully prepared a palladium-Schiff base complex by a simple and facile method from the reaction of 5-(1-methylimidazolium)vanillyl chloride with 3-aminopropyltriethoxysilane that had already been immobilized on GO. The catalytic activity of the $\mathrm{Pd}$ (II) Schiff-base/GO catalyst was examined in the reduction of nitrobenzene under mild conditions. This catalytic system offered high catalytic activity due to the distinctive properties of $\mathrm{GO}$ as a nanostructure support as well as the presence of palladium complex on the GO surface.

\section{Materials and methods}

\subsection{Materials}

All chemicals, and solvents were of analytical grade and were used without further purification. Graphite, 3aminopropyltriethoxysilane (3-APTES, 99\%), toluene (anhydrous, 99.8\%), ethanol ( $\geq 99.8 \%)$, nitrobenzene, sulfuric acid (99.99\%), phosphoric acid (85 wt. \% in $\mathrm{H}_{2} \mathrm{O}$ ), $\mathrm{KMnO}_{4}\left(\geq 99.0 \%\right.$ ), hydrogen peroxide (30 wt. \% in $\mathrm{H}_{2} \mathrm{O}$ ), palladium chloride, potassium chloride, and $\mathrm{NaBH}_{4}$ are purchased from Sigma Aldrich. In addition, 5-(1methylimidazolium)-vanillyl chloride was synthesized from o-vanillin and 1-methylimidazole according to the procedure reported in the literature [44].

\subsection{Characterization}

The FTIR spectra of the fabricated materials were performed in the range 400-4000 $\mathrm{cm}^{-1}$ using Bruker Vector 22 spectrometer ( $\mathrm{KBr}$ disc). XRD patterns were conducted on X'Pert Philips Diffractometer, applying the $\mathrm{Cu}-\mathrm{Ka}$ at $\lambda=1.54056 \AA$. The thermal assessment was conducted on Shimadzu-60 thermal analyzer with flow of nitrogen $\left(20 \mathrm{ml} / \mathrm{min}\right.$.) and 5 and $10{ }^{\circ} \mathrm{C} / \mathrm{min}$ heating rate up to $1000^{\circ} \mathrm{C}$. The elemental assessments was estimated on a CHN-analyzer (2400 PerkinElmer, USA). The surface morphologies analysis were iexaminedby scanning electron microscopy (SEM) (JEOL JSM-7100F). Transmission electron microscopy (TEM) images were obtained from a JEOL model 2100 instrument working at $200 \mathrm{kV}$.

\subsection{Synthesis}

\subsubsection{Preparation of graphene oxide (GO)}

Graphene oxide, GO, was prepared from graphite powder using modified Hummers method with slight modifications [45]. In brief, $0.3 \mathrm{~g}$ of graphite powder is added to the mixture of $25 \mathrm{ml}$ of conc. $\mathrm{H}_{2} \mathrm{SO}_{4}$ is blended with $2 \mathrm{ml}$ of $\mathrm{H}_{3} \mathrm{PO}_{4}$ with stirring for $15 \mathrm{~min}$. Then, $1.35 \mathrm{~g}$ of $\mathrm{KMnO}_{4}$ is slowly added, and then the temperature is raised to $50^{\circ} \mathrm{C}$. Continues agitation is needed for about three hours until the color of the solution turned to deep green. Then, the blend is placed to ice bath having $1.5 \mathrm{ml} \mathrm{H}_{2} \mathrm{O}_{2}$, and the solution is heated slowly to get ride the residual permanganate. The mixture was separated and rinsed with $30 \mathrm{~mL}$ of $\mathrm{HCl} / \mathrm{H}_{2} \mathrm{O}(1: 4, \mathrm{~V} / \mathrm{V})$. Finally, the $\mathrm{GO}$ was dispersed in diethyl ether overnight, separated, and dried at $50^{\circ} \mathrm{C}$.

\subsubsection{Preparation of $\mathrm{NH}_{2}$-functionalized graphene oxide $\left(\mathrm{NH}_{2}-\mathrm{GO}\right)$}

$\mathrm{NH}_{2}$-GO was fabricated by grafting 3-aminopropyltriethoxysilane (3-APTES) on graphene oxide targeting their hydroxyl and carboxylic groups [46]. The as-prepared GO (100 mg, $50 \mathrm{~mL}$ ) was suspended by sonication in anhydrous toluene. Subsequently, $2.3 \mathrm{mmol}$ of 3-APTES was poured to the dispersed graphene oxide and the blend was heated at $110^{\circ} \mathrm{C}$ for $24 \mathrm{~h}$ under $\mathrm{N}_{2}$ protection (Scheme 1). After filtration, the solid, denoted as $\mathrm{NH}_{2}-\mathrm{GO}$, was washed with toluene 4 times for removing undigested APTES and the $\mathrm{NH}_{2}-\mathrm{GO}$ was dried at $60^{\circ} \mathrm{C}$.

\subsubsection{Preparation of Palladium(II) Schiff-base complex}

$0.5 \mathrm{~g}$ of the prepared $\mathrm{NH}_{2}$-GO was sonicated with $100 \mathrm{~mL}$ ethanol using an ultrasonic technique and then $1.0 \mathrm{~g}$ of 5(1-methylimidazolium)-vanillyl chloride reagent was added. The reaction mixture was heated for $8 \mathrm{~h}$ under nitrogen gas. After reaction completion, the resulting product was centrifuged and rinsed four times by ethanol 
to eliminate the unreacted reagent. In order to prepare the palladium complex, $\mathrm{PdCl}_{2}(0.2 \mathrm{~g})$ and an excess amount of $\mathrm{KCl}(50 \mathrm{mg})$ were dissolved in deionized water $(10 \mathrm{~mL})$ with stirring at room temperature for $15 \mathrm{~min}$. Finally, $0.5 \mathrm{~g}$ of the obtained Schiff-base/GO was added and the mixture was continuously stirring at ambient temperature overnight (Scheme 1). After centrifugally separation, the prepared complex was washed five times with water.

\subsubsection{Catalytic reduction of nitrobenzene}

In order to examine the catalytic performance of the $\mathrm{Pd}$ (II) Schiff-base/GO catalyst, the reduction of nitrobenzene using $\mathrm{NaBH}_{4}$ was studied as a typical reaction in the aqueous phase. Firstly, freshly prepared aqueous solution of $\mathrm{NaBH} 4$ ( $5 \mathrm{mg}$ in $1 \mathrm{~mL}$ ice water) was mixed with $5 \mathrm{~mL}$ of $2.5 \times 10^{-4} \mathrm{~mol} \mathrm{~L}^{-1}$ nitrobenzene in $5 \mathrm{~mL}$ deionized water placed in a plastic tube. Then, $1 \mathrm{mg}$ of the $\mathrm{Pd}$ (II) Schiff-base/GO catalyst was added into the mixture and the reduction of nitrobenzene was started at the moment of catalyst addition. The success of the reaction was followed by evaluating a slight portion of the reaction mixture at determined estimated time intervals in the UV vis-spectrophotometer a shimadzu 2600 . The catalyst was separated from the mixture at the completion of the reaction so that it can assess its recyclability. The catalyst separation was carried out by centrifugation and rinsed with distilled water and ethanol for four times to get rid of any adsorbed molecules. The recycled catalyst was added to another freshly prepared solution of nitrobenzene and $\mathrm{NaBH}_{4}$ and the next reaction run is started. The durability examination was performed in four consecutive catalytic cycles.

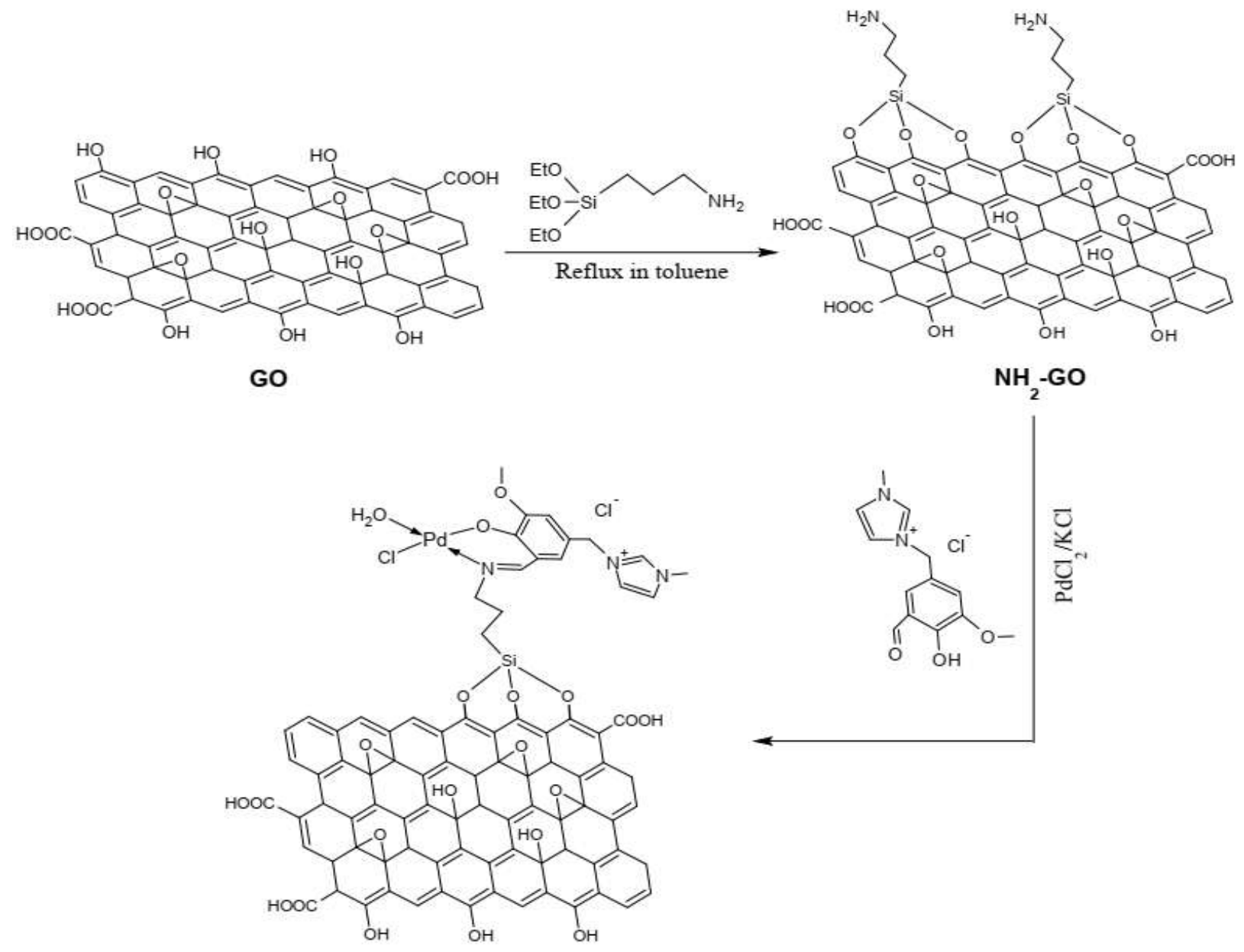

Pd(II) Schiff-base/GO

Scheme 1. Synthesis of $\mathrm{Pd}(\mathrm{II})$ Schiff-base/GO catalyst 


\section{Results and discussion}

\subsection{Materials Characterization}

The magnitude of elemental assessment of $\mathrm{C}, \mathrm{H}$, and $\mathrm{N}$ elements given by $\mathrm{CHN}$ analysis for the prepared samples are shown in Table 1. The amount of nitrogen in the amino-functionalized GO is $7.07 \%$ identifying that the amino groups are successfully introduced on the GO surface. The FTIR spectral data of $\mathrm{GO}, \mathrm{GO}-\mathrm{NH}_{2}$ and $\mathrm{Pd}(\mathrm{II})$ Schiff-base/GO samples are shown in Fig. 1. For $\mathrm{GO}$, three mainly bands are detected ascribed to oxygenated functional moieties $-\mathrm{OH}, \mathrm{C}=\mathrm{O}$ and epoxy moieties at 3443,1631 and $1032 \mathrm{~cm}^{-1}$, respectively. Also, the peak at $2924 \mathrm{~cm}^{-1}$ related to $\mathrm{C}-\mathrm{H}$ vibration mode of aromatic ring in graphene oxide. The spectrum of $\mathrm{NH}_{2}-$ GO contains some further bands can be related to emphasize the silylation process; the peak due to stretching mode of $\mathrm{N}-\mathrm{H}$ at $3442 \mathrm{~cm}^{-1}$ and the bending band at $1517 \mathrm{~cm}^{-1}$ ascribed to a primary amine. The peaks at 2960 and $2925 \mathrm{~cm}^{-1}$ assigned to the symmetric and asymmetric stretching of $-\mathrm{CH}_{2}$ group within the APTES. Successful grafting of graphene oxide with amino groups through chemical bonding consequence in the bands at 1111 and $1034 \mathrm{~cm}^{-1}$ which ascribed to the vibration of $\mathrm{Si}-\mathrm{O}$, and the apparent stretching modes of $\mathrm{Si}-\mathrm{O}-\mathrm{C}$ at $698 \mathrm{~cm}^{-1}$, respectively. The FTIR spectrum of $\mathrm{Pd}$ (II) Schiff-base/GO displays an extra peak at about $1618 \mathrm{~cm}^{-1}$ attributing to $\mathrm{C}=\mathrm{N}$ stretching, indicating that the Schiff-base was successfully immobilized onto GO.
Table 1. $\mathrm{CHN}$ analysis of the fabricated materials

\begin{tabular}{c|c|c|c}
\hline Sample & $\mathbf{C} \%$ & $\mathbf{H} \%$ & $\mathbf{N} \%$ \\
\hline GO & 33.77 & 2.70 & 1.87 \\
GO-NH & 23.04 & 4.85 & 7.07 \\
Pd(II) Schiff-base/GO & 25.51 & 3.36 & 5.10 \\
\hline
\end{tabular}

Raman spectroscopy is broadly applied non-destructive characterization key to emphasize ordered/disordered crystal structure and electronic characteristics of graphitic materials. The $D$ and $G$ bands are familiar features of Raman carbon spectra. The $\mathrm{G}$ band corresponds to $\mathrm{sp}^{2}$ carbon lattice and the $D$ band assigned to graphitic domain defects. The Raman spectra of $\mathrm{GO}$ and $\mathrm{Pd}(\mathrm{II})$ Schiff-base/GO complex are shown in Fig. 2. GO shows D band and $G$ band at 1352 and $1584 \mathrm{~cm}^{-1}$, respectively. The spectrum of the as-prepared catalyst exhibits a redshifted D band at $1340 \mathrm{~cm}^{-1}$, indicating the introduction of defect and disorder of the in-plane $\mathrm{sp}^{2}$ domains. The ratio of the intensity of the $D$ band to the $G$ band $\left(I_{D} / I_{G}\right)$ is regarded as an essential attribute that can be used as a measure of goodness of the graphitic structures where the value of $I_{D} / I_{G}$ is approaching zero for defect-free graphene [47]. In $\mathrm{Pd}(\mathrm{II})$ Schiff-base/GO, the value of $\mathrm{I}_{\mathrm{D}} / \mathrm{I}_{\mathrm{G}}(1.07)$ increases compared with that in $\mathrm{GO}(0.88)$, suggestion an increased disorder in the lattice of graphene after GO decoration.

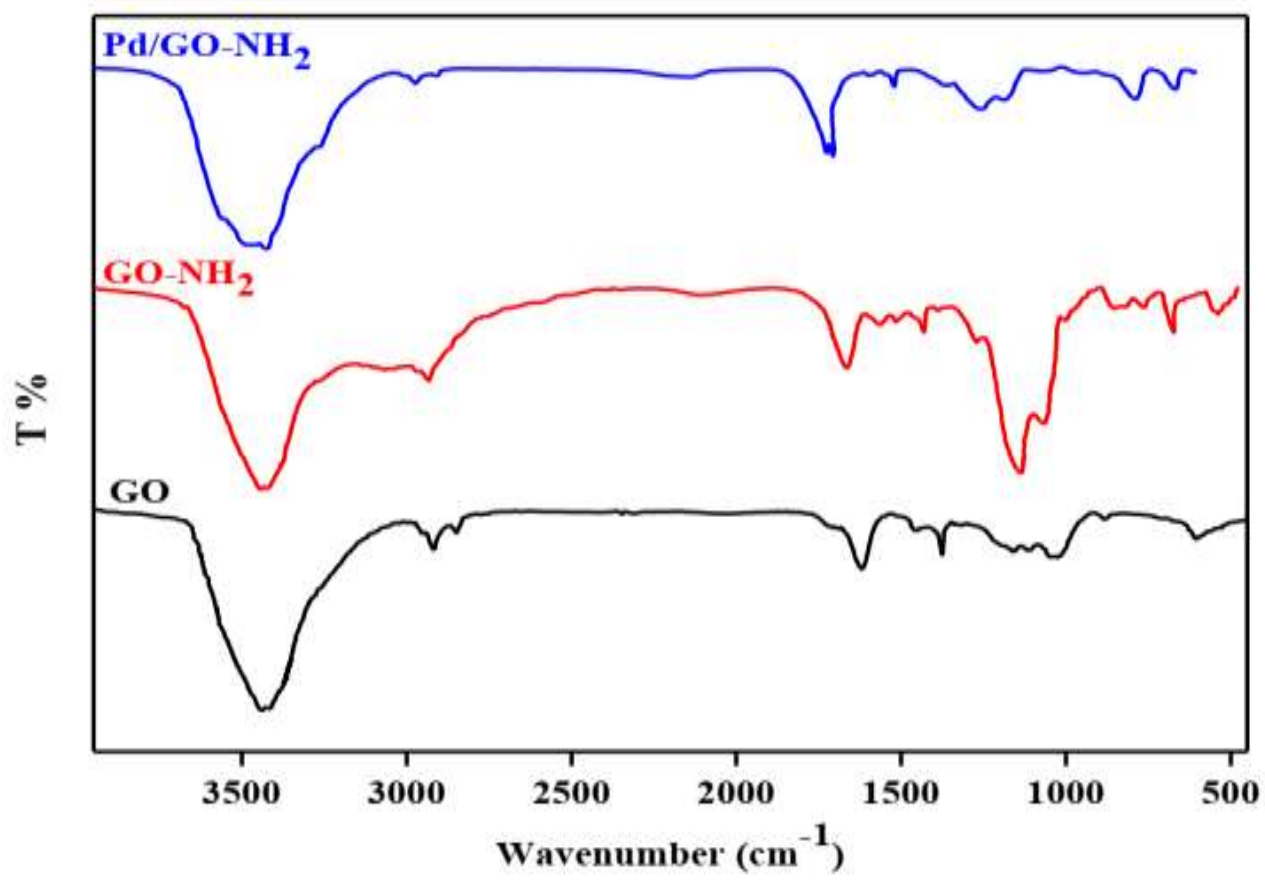

Fig. 1. FTIR spectra of $\mathrm{GO}, \mathrm{NH}_{2}-\mathrm{GO}$, and $\mathrm{Pd}(\mathrm{II})$ Schiff-base/GO complex 


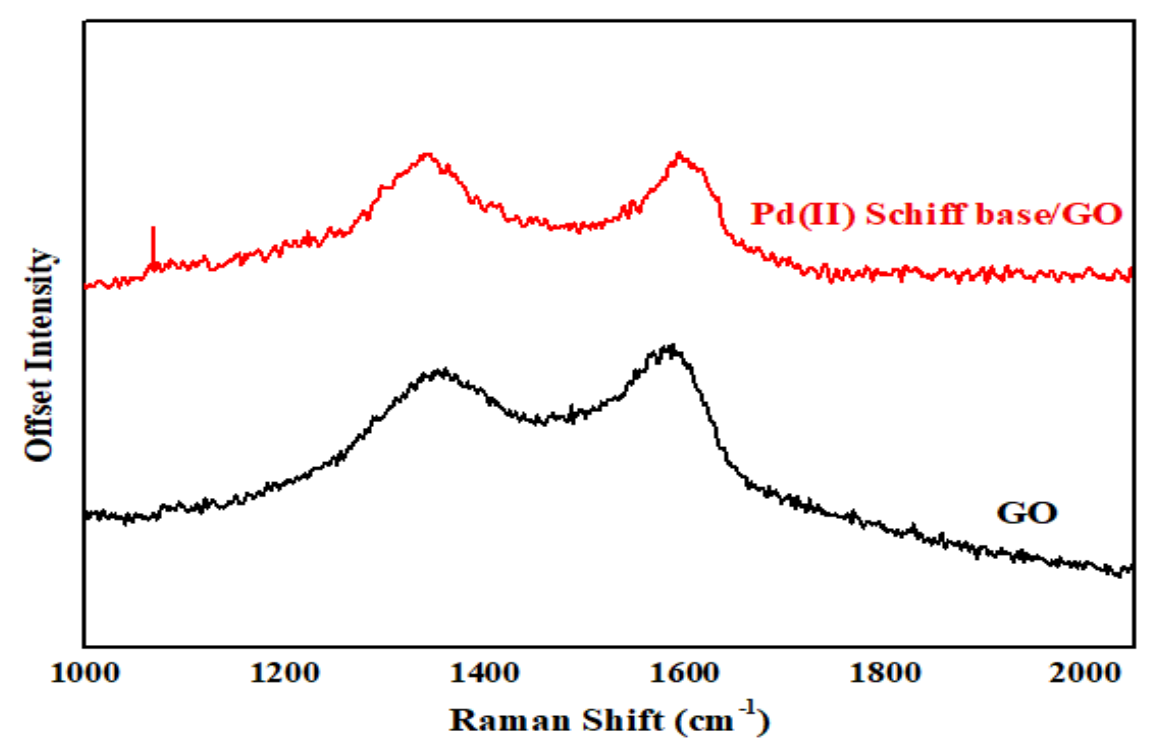

Fig. 2. Raman spectra of $\mathrm{GO}$ and $\mathrm{Pd}(\mathrm{II})$ Schiff-base/GO complex

The crystalline nature of prepared $\mathrm{GO}$ and $\mathrm{Pd}(\mathrm{II})$ Schiff-base/GO complex was investigated through the powder XRD technique. In our previous work [48], the diffraction pattern of GO showed the characteristic peak at $2 \theta=11.13^{\circ}$ with $\mathrm{d}$-spacing of $0.782 \mathrm{~nm}$ with reference to the distinctive peak of bulk graphite at about $26^{\circ}$ with corresponding to interlayer spacing of $0.343 \mathrm{~nm}$. These results confirmed worthy exfoliation of graphite sheets and successful insertion of oxygenated functional groups between GO layers. Furthermore, the amine functionalized GO demonstrated a broad peak at $21.9^{\circ}$ related to amorphous silica layer with decrease in the intensity of the peaks. Fig. 3 reveals the XRD pattern for the $\mathrm{Pd}(\mathrm{II})$ Schiff base/GO catalyst that clarifies appearance of a new peak at $2 \theta=26.23^{\circ}$, indicating the synthesis of palladium complex.

The thermal stability of the catalytic systems is a desirable property in recycling process. Therefore, the TGA plots of $\mathrm{GO}, \mathrm{NH}_{2}-\mathrm{GO}$ and $\mathrm{Pd}$ (II) Schiff-base/GO complex are depicted in Fig. 4 to explore their thermal stability. The TG profile of GO displays three different steps. The observed weight loss of about 25 percent underneath $150^{\circ} \mathrm{C}$ proved the water evaporation that are held in the sample. The second significant mass loss is noticed in the range of $150-350{ }^{\circ} \mathrm{C}$ was approximately 30 percent and owing to the thermal decomposition of labile oxygenated functional moieties [49]. The more stable oxygen fragments were eliminated at higher temperatures in the range of $450-650{ }^{\circ} \mathrm{C}$ (32 percent) [50]. For the amino-functionalized $\mathrm{GO}$ and the $\mathrm{Pd}$ (II) Schiff-base/GO complex, the curves showed a small weight loss at $150^{\circ} \mathrm{C}$ related to the desorption of water molecules from their surfaces ( 8 and 5 percent, respectively), which is lower than GO. Moreover, the APTES grafted GO had two more significant weight losses. The first was around 23 percent in the temperature range of $250-400{ }^{\circ} \mathrm{C}$ ascribed to the decomposition of undigested oxygen carrying parts on GO surface that have not shared in the interaction with APTES. The other major mass loss (37 percent) starts at $400{ }^{\circ} \mathrm{C}$ owing to the decomposition of APTES groups. The $\mathrm{Pd}$ (II) Schiff-base complex thermograph displays a weight loss of approximately 49 percent over a large temperature range from $150-600^{\circ} \mathrm{C}$ owing to the decomposition of the Schiff base complex [51]. Finally, the total weight loss for GO, $\mathrm{NH}_{2}-\mathrm{GO}$ and $\mathrm{Pd}(\mathrm{II})$ Schiff-base/GO samples were about 95, 72, and 56 percent, respectively. These results exhibited high thermal stability for the $\mathrm{Pd}(\mathrm{II})$ Schiffbase/GO catalyst, and the coordination between palladium and the imidazolium Schiff-base ligand revealed a good stability.

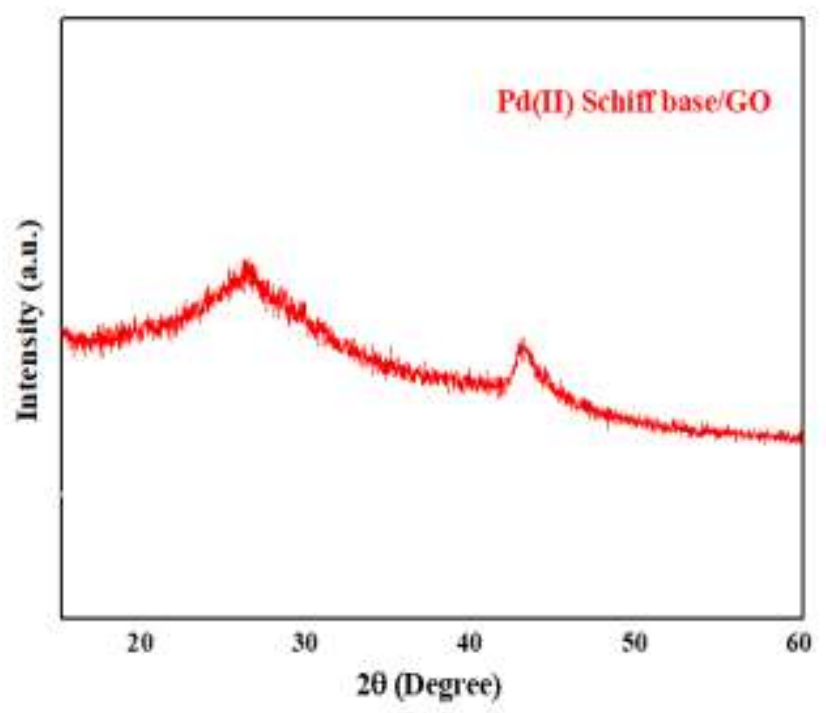

Fig. 3. XRD pattern of $\mathrm{Pd}(\mathrm{II})$ Schiff-base/GO complex 


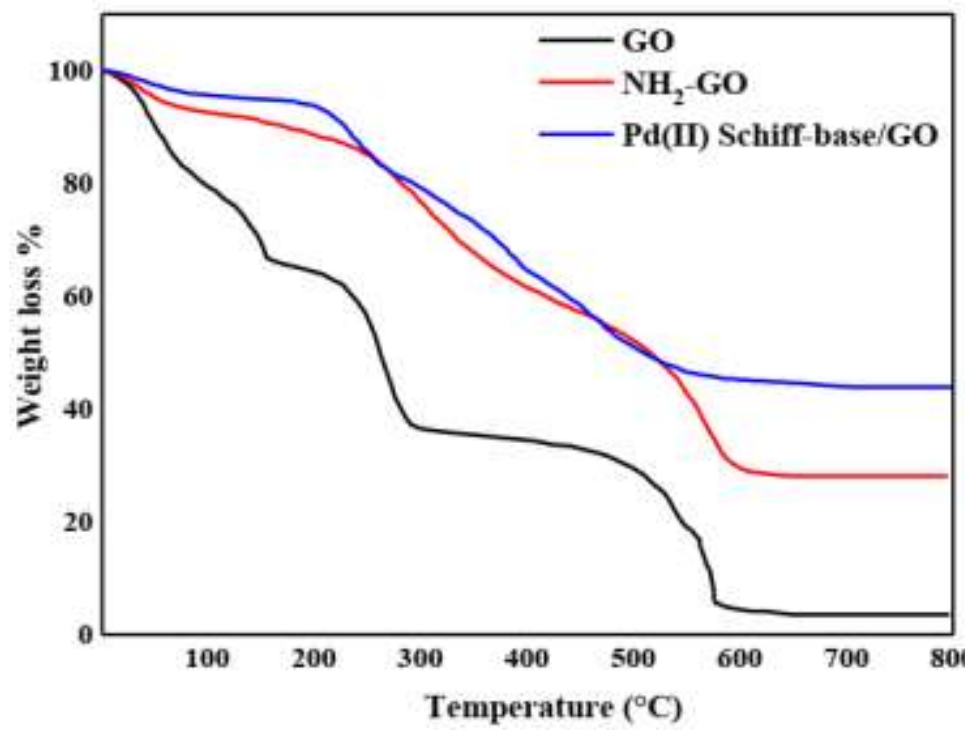

Fig. 4. TGA profiles of the fabricated materials

Fig. 5 represents the SEM and TEM images of the obtained materials.
The SEM image of GO (Fig. 5a) shows crumpledlayered structure and smooth surface. Heavy wrinkled flakes are observed in GO layers and edges (Fig. 5b) referring to the $\mathrm{Pd}$ complex immobilized on aminefunctionalized GO. The TEM image in Fig. $5 c$ exhibits the existence of the $\mathrm{Pd}$ complex without any change of layered structure of $\mathrm{GO}$.

\subsection{Catalytic activity of Pd(II) Schiff-base/GO}

The catalytic hydrogenation of nitrobenzene into aniline in the existence of $\mathrm{NaBH}_{4}$ at ambient temperature was performed as a model reaction to test the catalytic efficiency and flexibility of the $\mathrm{Pd}$ (II) Schiff-base/GO catalyst. Fig. 6 shows the UV-Vis absorption spectra of nitrobenzene, aniline, and the as-prepared $\mathrm{Pd}(\mathrm{II})$ catalyst. It is exhibited that nitrobenzene and aniline display intensive absorption bands at $266 \mathrm{~nm}$ and $230 \mathrm{~nm}$, respectively [52]. Moreover, the addition of pure GO causes a quick reduce in the intensity of the nitrobenzene band at $266 \mathrm{~nm}$, which is not accompanied, by any new peak for aniline. It would be attributed to the good and rapid adsorption of nitrobenzene substrate on the surface of GO.
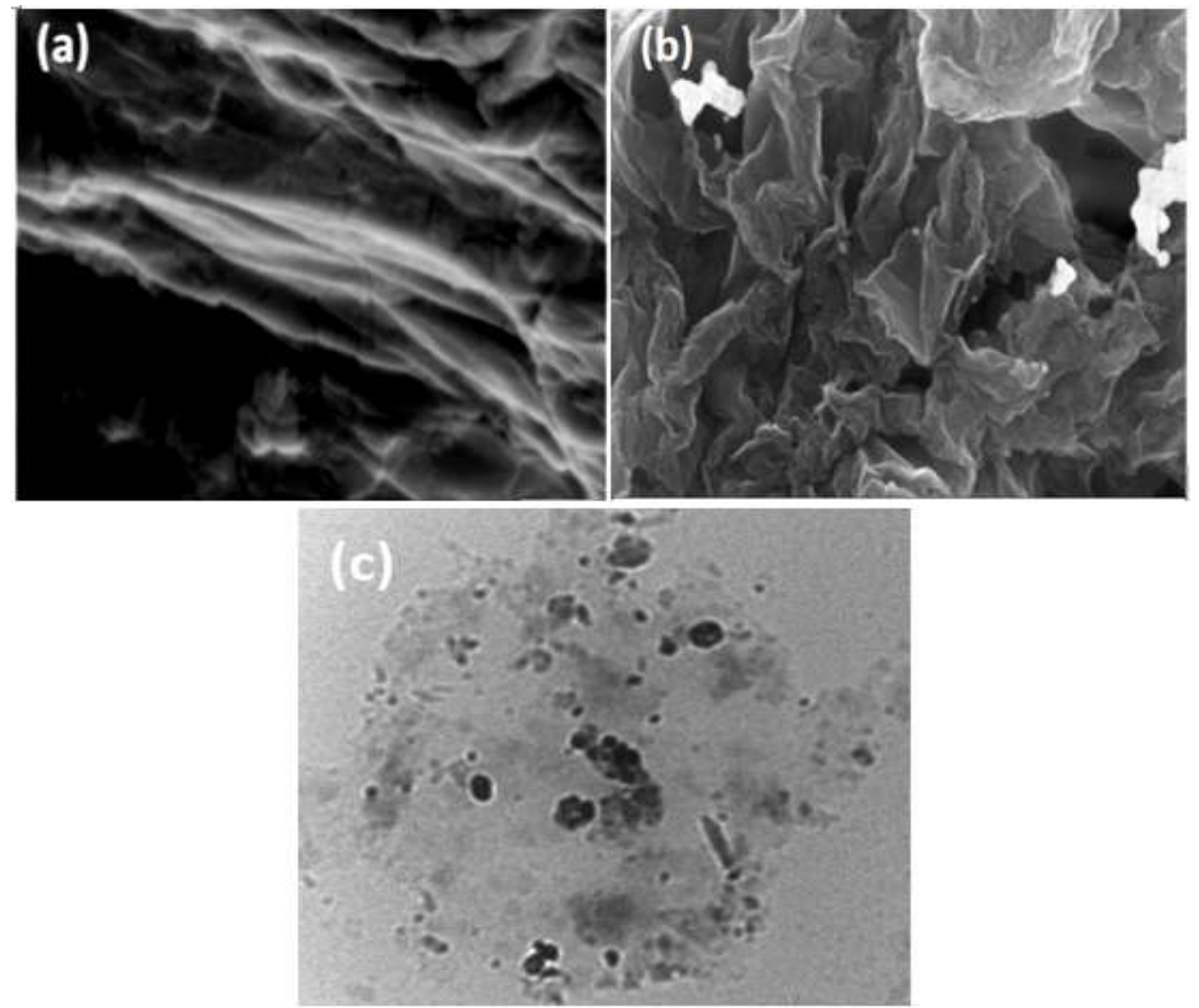

Fig. 5. SEM images of (a) GO (b) Pd(II) Schiff-base/GO complex (c) TEM image of Pd(II) Schiff-base/GO complex 


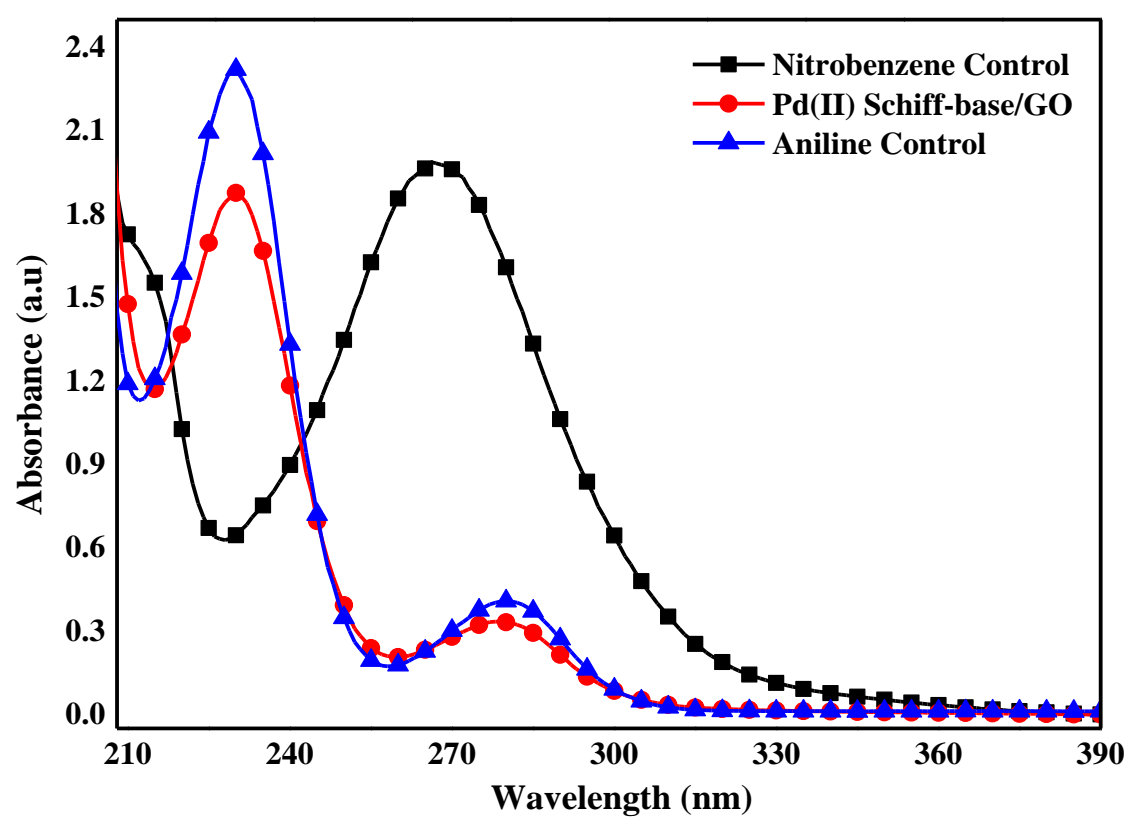

Fig. 6. UV-vis absorption spectra of nitrobenzene, aniline, and Pd(II) Schiff-base/GO catalyst

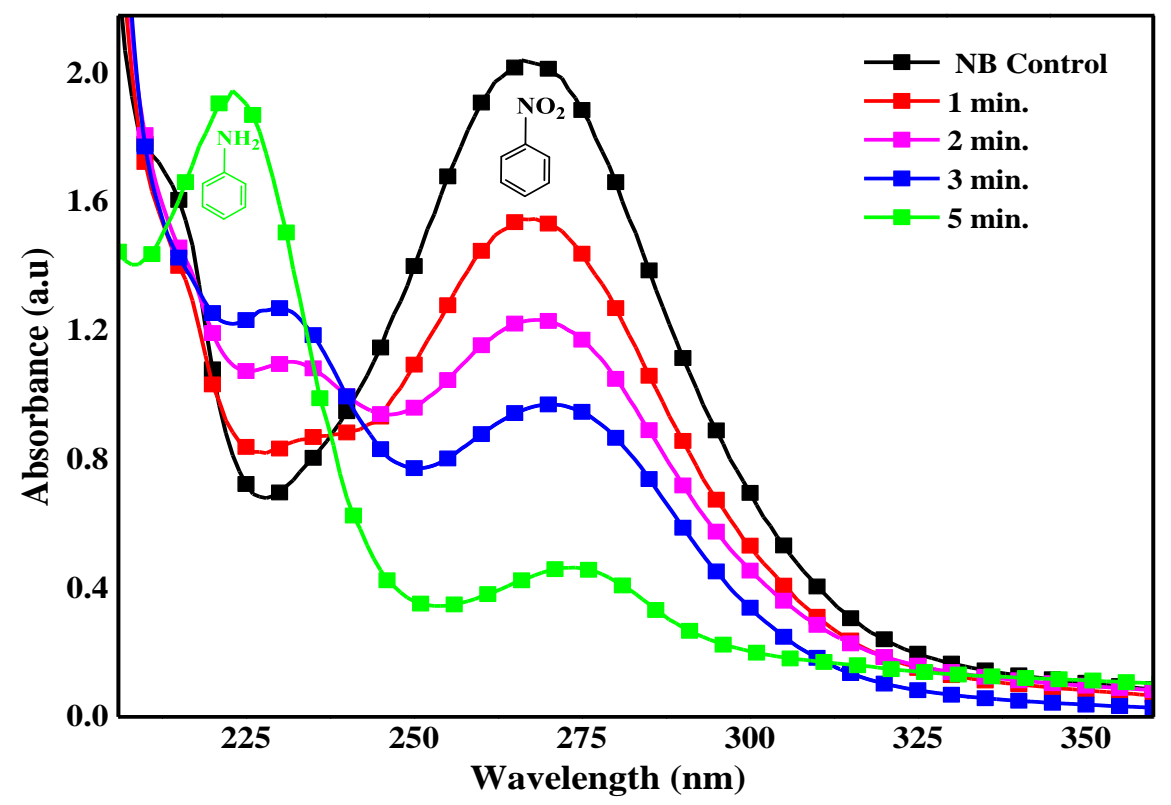

Fig. 7. UV-vis absorption spectra displaying gradual reduction of nitrobenzene (NB) over Pd(II) Schiff base/GO (2 mg catalyst, $5 \mathrm{mg} \mathrm{NaBH}_{4}, 3.5 \times 10^{-4} \mathrm{molL}^{-1} \mathrm{NB}$ ) 
As revealed in Fig. 7, the reduction of nitrobenzene could be easily investigated by the time-dependent UV-Vis absorption spectra. After the insertion of the Pd(II) Schiffbase/GO catalyst to the reaction mixture, the absorbance band of nitrobenzene at $266 \mathrm{~nm}$ slightly decreases in intensity with a simultaneous increase in the new band at $230 \mathrm{~nm}$ upon increasing reaction time that is ascribed to aniline product. The $\mathrm{Pd}(\mathrm{II})$ Schiff-base/GO catalyst showed superb catalytic activity in the reduction of nitrobenzene (Fig. 7). The reaction reached almost 96\% completion after $5 \mathrm{~min}$. This outstanding catalytic efficiency of the $\mathrm{Pd}$ (II) Schiff-base/GO catalyst is mainly related to the adsorption power of GO support towards nitrobenzene through $\pi-\pi$ interactions due to the distinctive properties of the two dimensional crystal structure of GO. This provides a high concentration of nitrobenzene reactant on the surface of the catalyst close to the $\mathrm{Pd}(\mathrm{II})$ ions that speeds up the reaction. Furthermore, GO has the ability to easily transfer electrons into the $\mathrm{Pd}(\mathrm{II})$ center encouraging the uptake of electrons by nitrobenzene molecules.

\subsubsection{Kinetic study}

The kinetic study of the catalytic reduction of nitrobenzene over Pd(II) Schiff-base/GO nanocomposite was investigated to detect the catalytic properties of the catalyst. The large excess of the initial concentration of $\mathrm{NaBH}_{4}$ compared to nitrobenzene supposed this concentration to be remained constant until the end of the reaction. Consequently, the pseudo-first-order reaction kinetic model was applied [53]. The rate constant (k) for the pseudo-first-order reaction could be estimated from the equation

$$
-\ln \left(\frac{C}{C_{0}}\right)=k t
$$

where $\mathrm{C}_{\circ}$ and $\mathrm{C}$ are the initial concentration and the concentrations of nitrobenzene an any reaction time $t$, respectively. Fig. 8 displays the plot of $\ln \left(\mathrm{C} / \mathrm{C}_{0}\right)$ of nitrobenzene versus reaction time using $\operatorname{Pd}(\mathrm{II})$ Schiffbase/GO catalyst. The relevant result observed good linear correlation and the rate constant $(k)$ evaluated from the slope in Fig. 3 was found to be $0.321 \mathrm{~min}^{-1}$.

\subsubsection{Comparison with other catalysts}

For benchmarking the current work, the catalytic activity of $\mathrm{Pd}$ (II) Schiff-base/GO catalyst was compared with some earlier reported studies on the nitrobenzene hydrogenation of and the data are emphasized in Table 2. It is obvious from Table 2 that the rate of the catalytic reduction of nitrobenzene over $\mathrm{Pd}$ (II) Schiff-base/GO in the present work is superior when compared with variant catalytic systems.

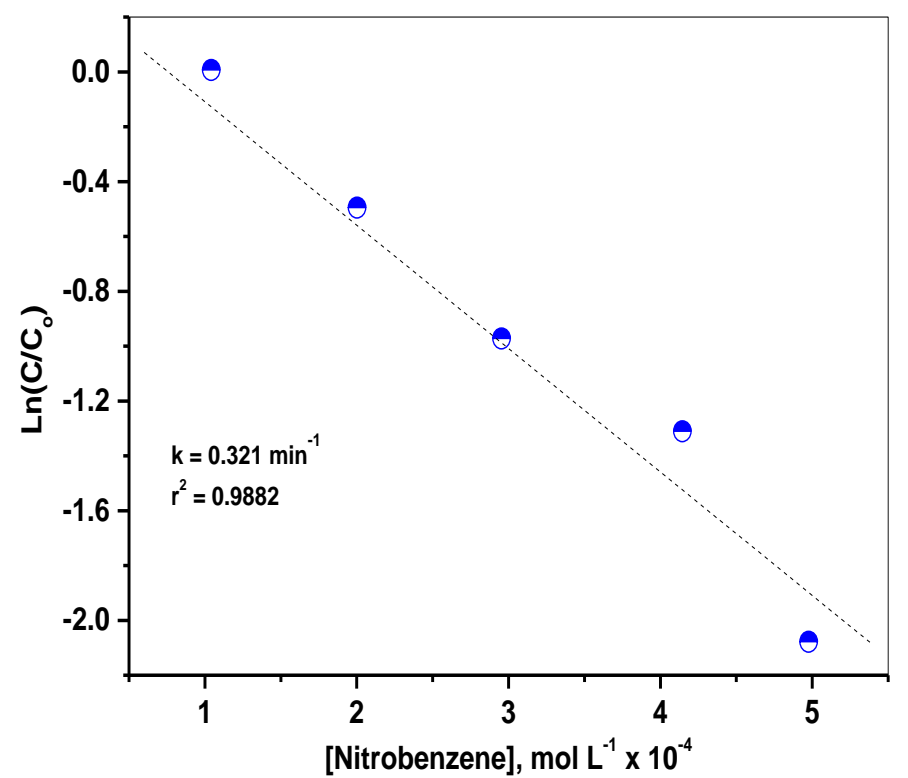

Fig. 8. Kinetics plot of $\ln \left(\mathrm{C} / \mathrm{C}_{0}\right)$ of nitrobenzene reduction versus time using $\mathrm{Pd}(\mathrm{II})$ Schiff base/GO catalyst

\subsubsection{Reusability of the Pd(II) Schiff-base/GO catalyst}

The recyclability is a crucial property in heterogeneous catalysts and it is an important factor in industrial applications from economical and environmental viewpoints. The $\mathrm{Pd}(\mathrm{II})$ Schiff-base/GO catalyst was recycled four consecutive times in the reduction of nitrobenzene under similar conditions (Fig. 9). As displayed in Fig. 9, the catalytic activity of the prepared catalyst is conserved without any significant loss of conversion percentage even after the fourth cycle at the same reaction time that indicate the good stability and persistence of the $\mathrm{Pd}$ (II) Schiff-base/GO catalyst.

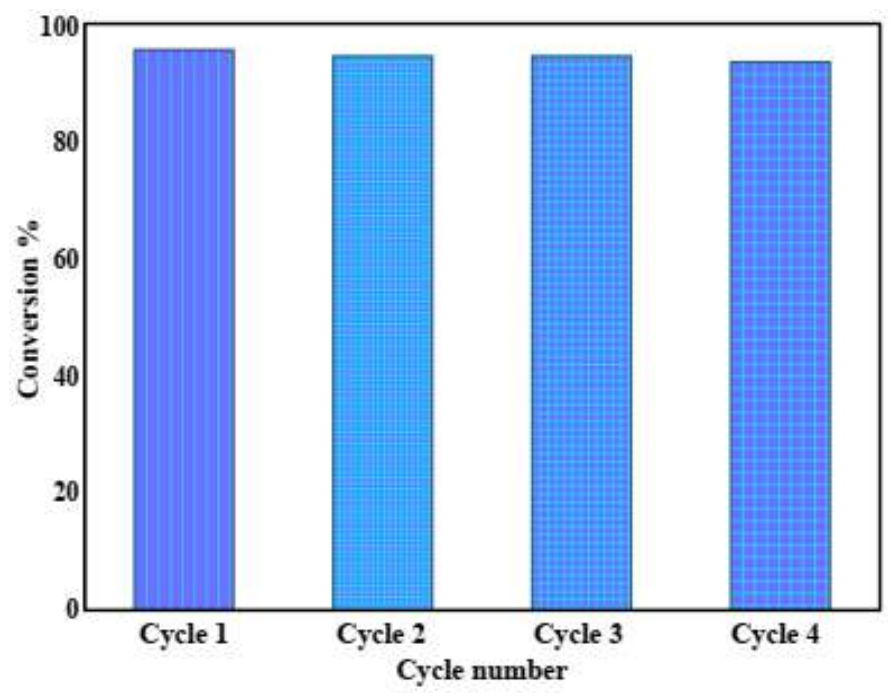

Fig. 9. Conversion (\%) of nitrobenzene reduction for each cycle using $\mathrm{Pd}$ (II) Schiff base/GO catalyst 
Table 2. Comparison of catalytic activity of $\mathrm{Pd}$ (II) Schiff-base/GO in nitrobenzene (NB) reduction with catalytic systems in previous studies.

\begin{tabular}{|c|c|c|c|c|}
\hline Catalyst & [NB], M & Reduction type & $\mathrm{K}, \min ^{-1}$ & Ref. \\
\hline Pd(II) Schiff-base/GO & $3.5 \times 10^{-4}$ & $\begin{array}{l}\text { Chemical reduction with } \\
\qquad \mathrm{NaBH}_{4}\end{array}$ & 0.321 & $\begin{array}{l}\text { Present } \\
\text { work }\end{array}$ \\
\hline Pd/graphitized C & $4 \times 10^{-4}$ & $\begin{array}{l}\text { Chemical reduction with } \\
\qquad \mathrm{NaBH}_{4}\end{array}$ & 0.24 & [54] \\
\hline Pd & $4 \times 10^{-4}$ & $\begin{array}{l}\text { Chemical reduction with } \\
\qquad \mathrm{NaBH}_{4}\end{array}$ & 0.079 & [54] \\
\hline $\mathrm{Pd} / \mathrm{Fe}_{3} \mathrm{O}_{4} @ \mathrm{C}$ & $4 \times 10^{-3}$ & $\begin{array}{l}\text { Chemical reduction with } \\
\qquad \mathrm{NaBH}_{4}\end{array}$ & $0.049^{a}$ & [55] \\
\hline $\mathrm{Pd} / \mathrm{Fe}_{3} \mathrm{O}_{4} @ \mathrm{C}$ & $4 \times 10^{-3}$ & $\begin{array}{l}\text { Chemical reduction with } \\
\qquad \mathrm{NaBH}_{4}\end{array}$ & $0.056^{\mathrm{b}}$ & [55] \\
\hline $\mathrm{Pd} / \mathrm{Fe}_{3} \mathrm{O}_{4} @ \mathrm{C}$ & $4 \times 10^{-3}$ & $\begin{array}{l}\text { Chemical reduction with } \\
\qquad \mathrm{NaBH}_{4}\end{array}$ & $0.14^{c}$ & [55] \\
\hline Nitrogen/porous carbon (NPC) & $8 \times 10^{-4}$ & Electrocatalytic reduction & 0.017 & [56] \\
\hline eosin $Y$ & $2 \times 10^{-4}$ & Photocatalytic reduction & $0.30^{d}$ & [57] \\
\hline eosin $Y$ & $2 \times 10^{-4}$ & Photocatalytic reduction & $0.28^{\mathrm{e}}$ & [57] \\
\hline
\end{tabular}

${ }^{\mathrm{a}} 20^{\circ} \mathrm{C},{ }^{\mathrm{b}} 40^{\circ} \mathrm{C},{ }^{\mathrm{c}} 60^{\circ} \mathrm{C},{ }^{\mathrm{d}}$ aerobic conditions, ${ }^{\mathrm{e}}$ anaerobic conditions.

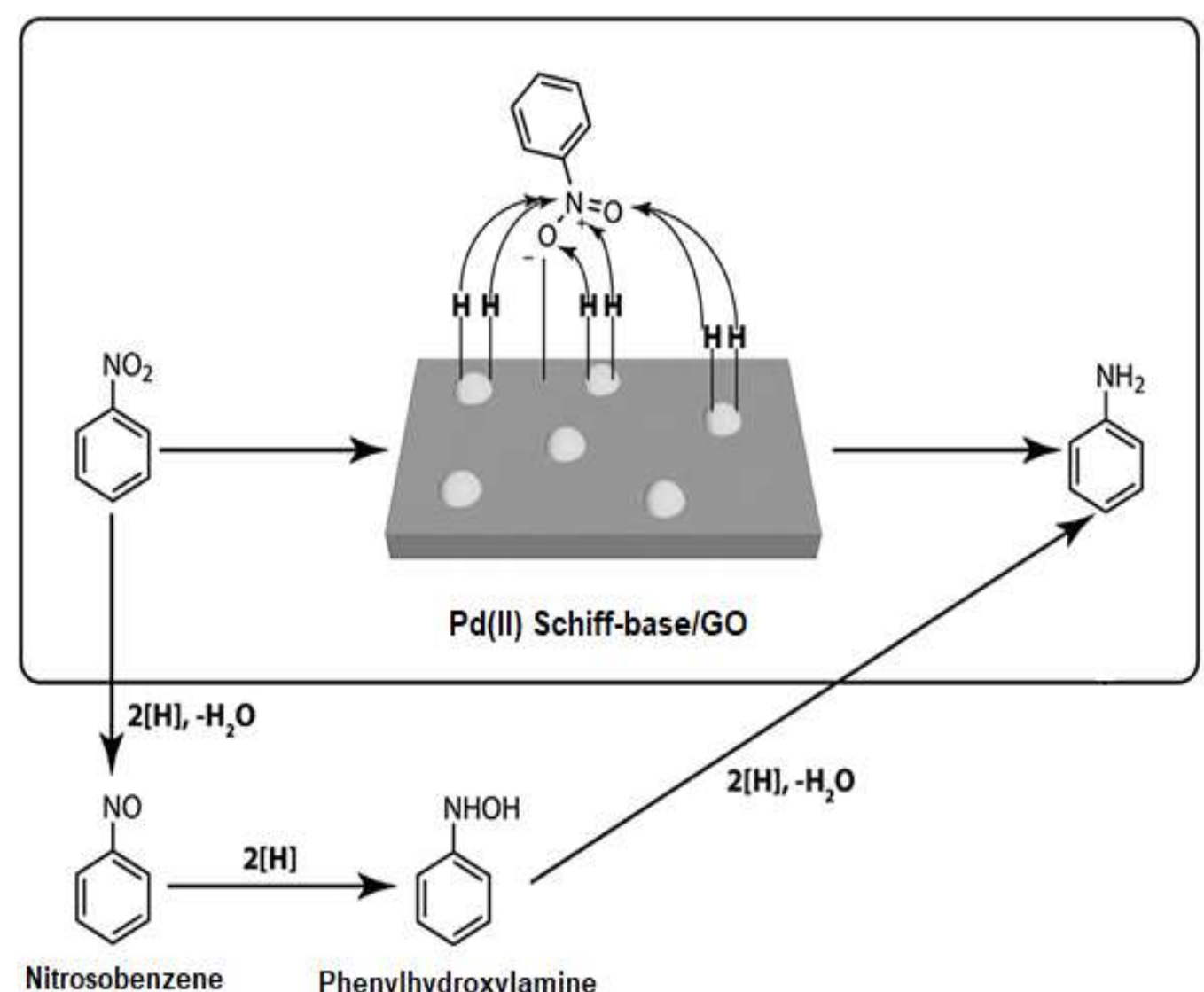

Scheme 2. Proposed mechanism for the reduction of nitrobenzene by $\mathrm{NaBH}_{4}$ in the presence of $\mathrm{Pd}(\mathrm{II}) \mathrm{Schiff}-\mathrm{base} / \mathrm{GO}$ catalyst. 
3.2.4 Proposed mechanism for the reduction of nitrobenzene

The reaction mechanism for the catalytic reduction of nitrobenzene involves several consecutive steps [58-61]. In the most acceptable mechanisms, phenylhydroxylamine is formed as an intermediate through the direct pathway. This reaction can be described as a proton-coupled hydride transfer. In the first step, $\mathrm{NaBH}_{4}$ is decomposed over the surface of the catalyst generating hydrogen gas. The following step is a proton-coupled hydride transfer from the active catalytic surface to the nitro group in nitrobenzene substrate that followed by dehydration to give a nitroso intermediate. The generation of hydrogen gas is occurred continuously at the surface of the catalyst. Moreover, a hydride attacks nitrosobenzene succeeded by protonation yielding the phenylhydroxylamine intermediate, which in turn is exposed to further proton-coupled hydride transfer and then dehydrated to finally yield an amino group in aniline. Hence, the suggested mechanism for the reduction of nitrobenzene using $\mathrm{NaBH}_{4}$ over $\mathrm{Pd}(\mathrm{II})$ Schiff-base/GO catalyst is illustrated in Scheme 2.

\section{Conclusion}

In summary, GO was exceptionally employed as a solid support for immobilizing a palladium Schiff-base complex as a potent heterogeneous catalyst for the reduction of nitrobenzene. The catalysts showed superior catalytic activity and durability. These findings seem to be attributed to the unique attributes of GO and the outstanding interactions between $\mathrm{Pd}(\mathrm{II})$ and the SchiffBase ligand.

\section{References}

[1] V. Kandathil, B. Kulkarni, A. Siddiqa, M. Kempasiddaiah, B. S. Sasidhar, S. A. Patil, S. A. Patil, Catal. Lett. 150 (2020) 384403.

[2] J. Xia, G. He, L. Zhang, X. Sun, X. Wang, Appl. Catal. B: Environ. 180 (2016) 408-415.

[3] B. Dutta, S. Biswas, V. Sharma, N. O. Savage, S. P. Alpay, S. L. Suib, Angew. Chem. Int. Ed. 55 (2016) 2171-2175.

[4] X. Sun, A.I. Olivos-Suarez, D. Osadchii, M.J.V. Romero, F. Kapteijn, J. Gascon, J. Catal. 357 (2018) 20-28.

[5] A. Goyal, S. Bansal, S. Singhal, Int. J. Hydrogen Energy 39 (2014) 4895-4908.

[6] E. Akbarzadeh, H. Z. Soheili, M. R. Gholami, Mater. Chem. Phys. 237 (2019) 121846.

[7] Y. Liu, Y. Lu, M. Prashad, O. Repi, T. J. Blacklock, Adv. Synth. Catal. 347 (2005) 217-219.

[8] X. Huang, Z. Zhao, J. Fan, Y. Tan, N. J. Zheng, Am. Chem. Soc. 133 (2011) 4718-4721.

[9] M. Aazza, H. Ahlafi, H. Moussout, C. Mounir, A. Fadel, A. Addad, J. Environ. Chem. Eng. 8 (2020) 103707.

[10] R. Dey, N. Mukherjee, S. Ahammed, B. C. Ranu, Chem. Commun. 48 (2012) 7982-7984.

[11] M. Li, L. Hu, X. Cao, H. Hong, J. Lu, H. Gu, Chem. Eur. J. 17 (2011) 2763-2768.

[12] R. G. D. Noronha, C. C. Romao, A. C. Farnandes, J. Org. Chem. 74 (2009) 6960-6964.

[13] M. Rocha, C. Fernandes, C. Pereira, S.L.H. Rebelo, M.F.R. Pereira, C. Freire, RSC Adv. 5 (2015) 5131-5141.
[14] P. Zhang, C. Shao, Z. Zhang, M. Zhang, J. Mu, Z. Guo, Y. Liu, Nanoscale 3 (2011) 3357-3363.

[15] Y. Imura, K. Tsujimoto, C. Morita, T. Kawa, Langmuir 30 (2014) 5026-5030.

[16] S. I. El-Hout, S. M. El-Sheikh, H. M. A. Hassan, F. A. Harraz, I. A. Ibrahim, E. A. El-Sharkawy, Appl. Catal. A: Gen. 503 (2015) 176-185.

[17] M. Mohan, N. Mohan, D.K. Chand, J. Mater. Chem. A 3 (2015) 21167-21177.

[18] Z. Zhao, H. Yang, Y. Li, X. Guo, Green Chem. 16 (2014) 1274-1281.

[19] A. Corma and P. Serna , Science 313 (2006) ,332-334.

[20] E. Vasilikogiannaki, C. Gryparis, V. Kotzabasaki, I. N. Lykakis, M. Stratakis, Adv. Synth. Catal. 355 (2013) 907-911.

[21] C. Neeli, P. Puthiaraj, Y.-R. Lee, Y.-M. Chung, S.-H. Baeck, W.-S. Ahn, Catal. Today, 303 (2018) 227-234.

[22] S. Xu, X. Xi, J. Shi, S. Cao, J. Mol. Catal. A Chem. 160 (2000) 287-292.

[23] W.-G. Jia, M. Li, X.-T. Zhi, L.-L. Gao, J. Du, J. Mol. Struct. 1217 (2020) 128349.

[24] G. Zhu, J. Geng, L. Yan, Y.-K. Yuan, G.-Z. Han, Colloids Surf. A Physicochem. Eng. Asp. 580 (2019) 123697.

[25] P. Puthiaraj, W.-S. Ahn, Catal. Commun. 65 (2015) 91-95.

[26] C. B. Murray, C. R. Kagan, M. G. Bawendi, Annu. Rev. Mater. Sci. 30 (2000) 545-610.

[27] T. Baran, A. Menteş, J. Organomet. Chem. 803 (2016) 3038.

[28] J. M. M. Tengco, Y. K. Lugo-José, J. R. Monnier, J. R. Regalbuto, Catal Today 246 (2015) 9-14.

[29] C. Liu, R. Tan, N. Yu, D. Yin, Microporous Mesoporous Mater. 131 (2010) 162-169.

[30] K. Mori, Y. Miura, S. Shironita, H. Yamashita, Langmuir 25 (2009) 11180-11187.

[31] M. Ghiaci, F. Ansari, Z. Sadeghi, A. Gil, Catal. Commun. 21 (2012) 82-85.

[32] H. Wu, L. Zhuo, Q. He, X. Liao, B. Shi, Appl. Catal. A: Gen. 366 (2009) 44-56.

[33] N. Y. Baran, T. Baran, M. Nasrollahzadeh, R. S. Varma, J. Organomet. Chem. 900 (2019) 120916-120925.

[34] B. Yoon, C. M. Wai, J. Am. Chem. Soc. 127 (2005) 1717417175.

[35] Y. Qu, T. Chen, G. Wang, Appl. Surf. Sci. 465 (2019) 888894.

[36] Y. Yang, A. Reber, S. Gilliland, C. Castano, B. Gupton, S. Khanna, J. Catal., 360 (2018) 20-26.

[37] C. Bai, Q. Zhao, Y. Li, G. Zhang, F. Zhang, X. Fan, Catal. Lett. 144 (2014) 1617-1623.

[38] A. Pourjavadi, N. Safaie, S. H. Hosseini, C. Bennett, J. Indust. Eng. Chem. 83 (2016) 82-92.

[39] J. H. Park, F. Raza, S.-J. Jeon, H.-I. Kim, T. W. Kang, D.-B. Yim, J.-H. Kim, Tetrahedron Letters, 55 (2014) 3426-3430.

[40] O. Akhavan, E. Ghaderi, ACS Nano 4 (2010) 5731-5736.

[41] P. Sun, M. Zhu, K. Wang, M. Zhong, J. Wei, D. Wu, Z. Xu, H. Zhu, ACS Nano 7 (2012) 428-437.

[42] Y. Li, Q. Zhao, J. Ji, G. Zhang, F. Zhang and X. Fan, RSC Adv. 3 (2013) 13655-13658.

[43] K. C. Gupta, A. K. Sutar, Coord. Chem. Rev. 252 (2008) 1420-1450.

[44] R. F. M. Elshaarawy, G. A. Seif, M. E. El-Naggar, T. B. Mostafa, E. A. El-Sawi, Eur. Polym. J. 116 (2019) 210-221.

[45] D. C. Marcano, D. V. Kosynkin, J. M. Berlin, A. Sinitskii, Z. Sun, A. Slesarev, L. B. Alemany, W. Lu, J. M. Tour, ACS nano, 4 (2010) 4806-4814.

[46] Q. Zhao, D. Chen, Y. Li, G. Zhang, F. Zhang and X. Fan, Nanoscale 5 (2013) 882-885. 
[47] C. Casiraghi, A. Hartschuh, H. Qian, S. Piscanec, C. Georgi, A. Fasoli, K.S. Novoselov, D.M. Basko, A.C. Ferrari, Nano Letters 9 (2009) 1433-1441.

[48] H. M. A. Hassan, M. A. Betiha, E. A. El-Sharkawy, R. F. M. Elshaarawy, N. B. El-Assy, A. A. Essawy, A. M. Tolba, A. M. Rabie, Colloids Surf. A Physicochem. Eng. Asp. 591 (2020) 124520.

[49] M. Khan, A. H. Al-Marri, M. Khan, N. Mohri, S. F. Adil, A. AlWarthan, M. R. H. Siddiqui, H. Z. Alkhathlan, R. Berger, W. Tremel, M. N. Tahir, Rsc Adv. 4 (2014) 24119-24125.

[50] A. Ganguly, S. Sharma, P. Papakonstantinou, J. Hamilton, J Phys Chem C. 115 (2011) 17009-17019.

[51] H. Su, Z. Li, Q. Huo, J. Guan and Q. Kan, RSC Adv. 4 (2014) 9990-9996.

[52] S. Jayabal, R. Ramaraj, Appl. Catal. A 470 (2014) 369-375.

[53] P. Zhao, X. Feng, D. Huang, G. Yang, D. Astruc, Coord. Chem. Rev. 287 (2015) 114-136.

[54] Y.-j. Kim, R. Ma, D. A. Reddy, T. K. Kim, Appl. Surf. Sci. 357 (2015) 2112-2120.

[55] N. Mei, B. Liu, Int. J. Hydrog. Energy 41 (2016) 1796017966.

[56] X. Zhao, A. Li, X. Quan, S. Chen, H. Yu, S. Zhang, Chemosphere 238 (2020) 124636.

[57] J.-H. Wu1, F. Zhang, Sci. Total Environ. 710 (2020) 136322. [58] L. Jiang, Z. Zhang, Int. J. Hydrog. Energy 41 (2016) 2298322990.

[59] A. Mahata, R. K. Rai, I. Choudhuri, S. K. Singh, B. Pathak, Phys. Chem. Chem. Phys. 16 (2014) 26365-26374.

[60] A. Goswami, R. G. Kadama, J. Tuček, Z. Sofer, D. Bouša, R. S. Varma, M. B. Gawande, R. Zbořil, Chem. Eng. J. 382 (2020) 122469-122476.

[61] A. Corma, P. Concepción, P. Serna, Angew Chem Int Ed 46 (2007) 7266. 